http://dx.doi.org/10.35381/racji.v6i1.1423

\title{
Pornografía Infantil en Ecuador
}

\section{Child Pornography In Ecuador}

\author{
Pamilys Milagros Moreno-Arvelo \\ uq.pamilysmoreno@uniandes.edu.ec \\ Universidad Regional Autónoma de los Andes, Quevedo \\ Ecuador \\ https://orcid.org/0000-0001-8913-4352 \\ Julio César-de-Jesús Arrias-Añez \\ uq.julioarrias@uniandes.edu.ec \\ Universidad Regional Autónoma de los Andes, Quevedo \\ Ecuador \\ https://orcid.org/0000-0001-5259-9359 \\ Alianny Madelyne Espinoza-Mendoza \\ dq.aliannymem49@uniandes.edu.ec \\ Universidad Regional Autónoma de los Andes, Quevedo \\ Ecuador \\ https://orcid.org/0000-0002-1123-1088
}

Recepción: 15 de marzo 2021

Revisado: 25 de mayo 2021

Aprobación: 15 de junio 2021

Publicación: 01 de Julio 2021 


\title{
RESUMEN
}

El presente artículo científico trata sobre un problema que ha transcendido durante varios años en Ecuador y en el mundo entero, la pornografía infantil afecta a los niños, niñas y adolescentes, que los convierte víctimas de este tipo de delito. Por todo lo esbozado se planteó como objetivo general analizar las normas establecidas por el Estado ecuatoriano para la protección de los menores de edad de la pornografía. El trabajo investigativo se recorrió a partir del enfoque cuantitativo, mediante la búsqueda, recolección y análisis crítico documental, referencial bibliográfico y estudios de investigación. Desde un diseño bibliográfico de tipo documental, cuya pesquisa desde la deliberación crítica, se construyó el método de análisis del fenómeno de estudio, reflexionando leyes, normas, acuerdos, tratados internacionales, lo que llevó a la producción de información relevante sobre el tema investigado. Se concluye que el Estado debe crea un sistema más fuerte y resolver estos tipos de delitos.

Descriptores: Pornografía; abuso sexual; derechos del niño; derechos humanos; tráfico humano. (Palabras tomadas del Tesauro UNESCO).

\begin{abstract}
This scientific article deals with a problem that has transcended for several years in Ecuador and throughout the world, child pornography affects children and adolescents, which makes them victims of this type of crime. For all the above, the general objective was to analyze the norms established by the Ecuadorian State for the protection of minors from pornography. The investigative work was carried out from the quantitative approach, through the search, collection and critical analysis of documents, bibliographic references and research studies. From a bibliographic design of a documentary type, whose research from critical deliberation, the method of analysis of the study phenomenon was built, reflecting on laws, norms, agreements, international treaties, which led to the production of relevant information on the subject under investigation. It is concluded that the State must create a stronger system and solve these types of crimes.
\end{abstract}

Descriptors: Pornography; sexual abuse; children's rights; human rights; human traffic. (Words taken from the UNESCO Thesaurus). 


\section{INTRODUCCIÓN}

La presente investigación se desarrolla sobre uno de los delitos que en la actualidad se sigue cometiendo, como es la pornografía infantil, es un problema donde las víctimas del mismo son niños, niñas y adolescentes, es un inconveniente de carácter crítico. En la actualidad existen sanciones para las personas que realicen estos actos, y que muchas veces son presa fácil mediante los medios y redes sociales, ya que debido que las personas hoy en día se manejan por medios de las mismas, desde el más pequeño de la casa, por eso es necesario que desde muy infantes exista el control por medio de los progenitores o tutor encargado del mismo, ya que muchos no vigilan los lugares o sitios web que sus hijos visitan, ya que el internet hoy en día es un portal muy extenso donde se puede encontrar con facilidad lo que se esa buscando, al igual como acceder alguna red social ilegal e información distorsionada. Al respecto Astorga-Aguilar y Schmidt-Fonseca (2019) indican:

En la actualidad, a través de los medios de comunicación se conoce que las personas menores de edad están siendo engañadas, utilizadas en redes de prostitución infantil, secuestradas y violadas por "supuestas" amistades que hicieron en redes sociales y que no son más que perfiles falsos de personas pedófilas y degeneradas (p.4)

De acuerdo a los hechos de violación y vulneración de los menores, Sáenz (2020) describe las características del abuso sexual en los menores de edad son las siguientes:

1. La víctima es un menor de edad cuenta con menos de dieciocho años de edad, tomando en cuenta que dentro de este rango de edad el menor de catorce años, constituye una condición de agravante de la figura delictiva.

2. El bien jurídico afectado es la integridad sexual misma que forma parte de la personalidad del sujeto, siendo uno de los aspectos específicos la sexualidad de este.

3. Existe una ausencia del consentimiento o de la manifestación de voluntad de la víctima, ya que debido a su edad no está en condiciones de comprender las implicaciones del acto en sí.

4. Se da la presencia de intimidación del victimario hacia la víctima, que puede transformarse en una forma de violencia tanto sicológica como física. 
5. El victimario actúa con dolo, es decir, una intención directa de daño.

Otro de los elementos a considerar según Cruz Céspedes (2019):

Es importante destaca que el internet y redes sociales, son el cultivo perfecto para la generación de delitos relacionados a la pornografía infantil y abuso sexual, transcendiendo las fronteras del Ecuador, reseñándose como un delito de connotación global en donde los abusadores, toman diversas posiciones para poder cometer su fechoría sin ser detectados por las autoridades, familias e incluso por la propia víctima. (p.731)

Cabe recalcar que la pornografía infantil se la conoce como un negocio ilegal, que afecta todos los países, pues el número de niños que se tiene conocimiento que han sido víctimas de este delito, ya que no todos deciden a proceder hacer las respectivas denuncias por miedo a que sus agresores tomen algunas medidas que pongan en riesgo su vida y la de sus familiares, así que en su mayoría deciden simplemente callar e intentar seguir con sus vidas, aunque a muchos les crean traumas de por vida.

Según lo establecido en la Constitución de la República del Ecuador vigente desde el 2008, en su artículo 45.- establece: Las niñas, niños y adolescentes gozarán de los derechos comunes del ser humano, además de los específicos de su edad. El Estado reconocerá y garantizará la vida, incluido el cuidado y protección desde la concepción. (Asamblea Nacional, 2008). Como lo señala el párrafo anterior tipificado en nuestra Carta Magna se debe precautelar y garantizar el goce de los derechos de los niños, niñas y adolescentes, pues al ser un grupo vulnerable a la pornografía infantil se corresponde tener en cuenta las medidas para poder penalizar este problema. Para, Mayer (2014) la evidencia empírica relativa al comportamiento (futuro) de consumidores de material pornográfico en cuya producción se utilice a menores de edad, constituye información que debe ponderarse correctamente y emplearse con suma cautela.

Cabe señalar que la familia es considerada como el núcleo de la sociedad y referente al tema, todo niño, niña o adolescente que es víctima de este tipo actos de ilícitos, como la pornografía infantil, necesitaría a su familia en especial a sus padres, para poder sentir el apoyo de que no está solo, de sentir esa protección y con ayuda de 
especialistas y el amor de su familia podrá continuar con su vida y ser un profesional de bien en un futuro.

Por todo lo esbozado se planteó como objetivo general analizar las normas establecidas por el Estado ecuatoriano para la protección de los menores de edad de la pornografía.

\section{METODOLOGÍA}

El trabajo investigativo se recorrió a partir del enfoque cuantitativo, mediante la búsqueda, recolección y análisis crítico documental, referencial bibliográfico y estudios de investigación, desde la exégesis sobre la pornografía infantil de los niños, niñas y adolescentes en el contexto ecuatoriano, en este sentido, desde un diseño bibliográfico de tipo documental, cuya pesquisa desde la deliberación crítica, se construyó el método de análisis del fenómeno de estudio, reflexionando leyes, normas, acuerdos, tratados internacionales, lo que llevó a la producción de información relevante sobre el tema investigado. Al respecto, Villabela (2015, p.929) plantea, "muchos de los objetos con los que trabaja la ciencia jurídica pueden abordarse desde una dimensión teórica, empírica, cuantitativa o cualitativa, depende de cuál sea la arista que se estudia, y qué propósito tenga el investigador".

\section{RESULTADOS}

\section{Cuadro 1.}

Apoyo legal en la protección del menor.

\begin{tabular}{|c|c|c|}
\hline Normas legales & Artículo & Comentario \\
\hline $\begin{array}{l}\text { Constitución de la Republica del } \\
\text { Ecuador (2008) }\end{array}$ & $\begin{array}{l}\text { Art. 44.- El Estado, la sociedad } \\
\text { y la familia promoverán de } \\
\text { forma prioritaria el desarrollo } \\
\text { integral de las niñas, niños y } \\
\text { adolescentes, y asegurarán el } \\
\text { ejercicio pleno de sus derechos; } \\
\text { se atenderá al principio de su } \\
\text { interés superior y sus derechos } \\
\text { prevalecerán sobre los de las } \\
\text { demás personas. Las niñas, } \\
\text { niños y adolescentes tendrán } \\
\text { derecho a su desarrollo integral, } \\
\text { entendido como proceso de }\end{array}$ & $\begin{array}{l}\text { Partiendo de lo articulado cabe } \\
\text { recalcar que el deber primordial } \\
\text { que brinda el Estado a los } \\
\text { niños, niñas y adolescentes es } \\
\text { el desarrollo integral, } \\
\text { precautelando los demás } \\
\text { derechos, como a la vida, } \\
\text { educación, alimentación, } \\
\text { ambiente sano, entre otros, } \\
\text { pues en el caso que los niños } \\
\text { se ven afectados por estos } \\
\text { actos delictivos como es la } \\
\text { pornografía infantil, afecta su }\end{array}$ \\
\hline
\end{tabular}




\begin{tabular}{|c|c|c|}
\hline & $\begin{array}{l}\text { crecimiento, maduración y } \\
\text { despliegue de su intelecto y de } \\
\text { sus capacidades, } \\
\text { potencialidades y aspiraciones, } \\
\text { en un entorno familiar, escolar, } \\
\text { social y comunitario de } \\
\text { afectividad y seguridad. Este } \\
\text { entorno permitirá la satisfacción } \\
\text { de sus necesidades sociales, } \\
\text { afectivo-emocionales y } \\
\text { culturales, con el apoyo de } \\
\text { políticas intersectoriales } \\
\text { nacionales y locales. } \\
\text { Art. 81.- La ley establecerá } \\
\text { procedimientos especiales y } \\
\text { expeditos para el juzgamiento y } \\
\text { sanción de los delitos de } \\
\text { violencia intrafamiliar, sexual, } \\
\text { crímenes de odio y los que se } \\
\text { cometan contra niñas, niños, } \\
\text { adolescentes, jóvenes, } \\
\text { personas con discapacidad, } \\
\text { adultas mayores y personas } \\
\text { que, por sus particularidades, } \\
\text { requieren una mayor } \\
\text { protección. Se nombrarán } \\
\text { fiscales y defensoras o } \\
\text { defensores especializados para } \\
\text { el tratamiento de estas causas, } \\
\text { de acuerdo con la ley. }\end{array}$ & $\begin{array}{l}\text { entorno, poniendo en riesgo su } \\
\text { desarrollo causándole daños al } \\
\text { mismo, por eso es necesario } \\
\text { que este tipo de delito, se tome } \\
\text { en serio por las autoridades, } \\
\text { porque es algo que se viene } \\
\text { dando hasta la actualidad. }\end{array}$ \\
\hline $\begin{array}{l}\text { Código Orgánico integral Penal } \\
\text { (2014) }\end{array}$ & $\begin{array}{l}\text { Artículo 103.- Pornografía con } \\
\text { utilización de niñas, niños o } \\
\text { adolescentes. - La persona que } \\
\text { fotografíe, filme, grabe, } \\
\text { produzca, transmita o edite } \\
\text { materiales visuales, } \\
\text { audiovisuales, informáticos, } \\
\text { electrónicos o de cualquier otro } \\
\text { soporte físico o formato que } \\
\text { contenga la representación } \\
\text { visual de desnudos o } \\
\text { semidesnudos reales o } \\
\text { simulados de niñas, niños o } \\
\text { adolescentes en actitud sexual; } \\
\text { será sancionada con pena } \\
\text { privativa de libertad de trece a } \\
\text { dieciséis años. Si la víctima, } \\
\text { además, sufre algún tipo de } \\
\text { discapacidad o enfermedad } \\
\text { grave o incurable, se } \\
\text { sancionará con pena privativa } \\
\text { de libertad de dieciséis a } \\
\text { diecinueve años. Cuando la } \\
\text { persona infractora sea el padre, } \\
\text { la madre, pariente hasta el }\end{array}$ & $\begin{array}{l}\text { De acuerdo a los artículos } \\
\text { descritos del presente código } \\
\text { Orgánico Integral Penal, } \\
\text { sanciona dicha conducta } \\
\text { antijurídica como es la } \\
\text { pornografía infantil, a toda } \\
\text { persona que hago uso de } \\
\text { imágenes oncenas donde se } \\
\text { encuentre un niño, niña y } \\
\text { adolescente, pues cabe } \\
\text { recalcar que este tipo de } \\
\text { delitos, los mismos son los más } \\
\text { propensos a estos actos, } \\
\text { causando así daño, físico y } \\
\text { psicológico a la víctima, afecta } \\
\text { de esa manera su desarrollo. }\end{array}$ \\
\hline
\end{tabular}




\begin{tabular}{|c|c|c|}
\hline & $\begin{array}{l}\text { Cuarto grado } \\
\text { consanguinidad o segundo de } \\
\text { afinidad, tutor, representante } \\
\text { legal, curador o pertenezca al } \\
\text { entorno íntimo de la familia; } \\
\text { ministro de culto, profesor, } \\
\text { maestro, o persona que por su } \\
\text { profesión o actividad haya } \\
\text { abusado de la víctima, será } \\
\text { sancionada con pena privativa } \\
\text { de libertad de veintidós a } \\
\text { veintiséis años. } \\
\text { Artículo 104.- Comercialización } \\
\text { de pornografía con utilización } \\
\text { de niñas, niños o } \\
\text { adolescentes.- La persona que } \\
\text { publicite, compre, posea, porte, } \\
\text { transmita, descargue, } \\
\text { almacene, importe, exporte o } \\
\text { venda, por cualquier medio, } \\
\text { para uso personal o para } \\
\text { intercambio pornografía de } \\
\text { niños, niñas y adolescentes, } \\
\text { será sancionada con pena } \\
\text { privativa de libertad de diez a } \\
\text { trece años }\end{array}$ & \\
\hline $\begin{array}{l}\text { Código Orgánico de la niñez y } \\
\text { adolescencia (2003) }\end{array}$ & $\begin{array}{l}\text { Art. 11.- El interés superior del } \\
\text { niño. - El interés superior del } \\
\text { niño es un principio que está } \\
\text { orientado a satisfacer el } \\
\text { ejercicio efectivo del conjunto } \\
\text { de los derechos de los niños, } \\
\text { niñas y adolescentes; e impone } \\
\text { a todas las autoridades } \\
\text { administrativas y judiciales y a } \\
\text { las instituciones públicas y } \\
\text { privadas, el deber de ajustar } \\
\text { sus decisiones y acciones para } \\
\text { su cumplimiento. Para apreciar } \\
\text { el interés superior se } \\
\text { considerará la necesidad de } \\
\text { mantener un justo equilibrio } \\
\text { entre los derechos y deberes de } \\
\text { niños, niñas y adolescentes, en } \\
\text { la forma que mejor convenga a } \\
\text { la realización de sus derechos y } \\
\text { garantías. Este principio } \\
\text { prevalece sobre el principio de } \\
\text { diversidad étnica y cultural. El } \\
\text { interés superior del niño es un } \\
\text { principio de interpretación de la } \\
\text { presente Ley. Nadie podrá } \\
\text { invocarlo contra norma expresa } \\
\text { y sin escuchar previamente la } \\
\text { opinión del niño, niña o }\end{array}$ & $\begin{array}{l}\text { En este sentido, prexisten aún } \\
\text { debilidades en cuanto al } \\
\text { amparo del niño, niñas y } \\
\text { adolescente quebrantando en } \\
\text { cierto grado el principio de } \\
\text { interés superior. } \\
\text { emplazamiento es al Estado y } \\
\text { sus organismos para que } \\
\text { reestablezca los correctivos } \\
\text { necesarios y ofrecer en una } \\
\text { gran medida el acatamiento de } \\
\text { las normas y protección de los } \\
\text { menores. }\end{array}$ \\
\hline
\end{tabular}




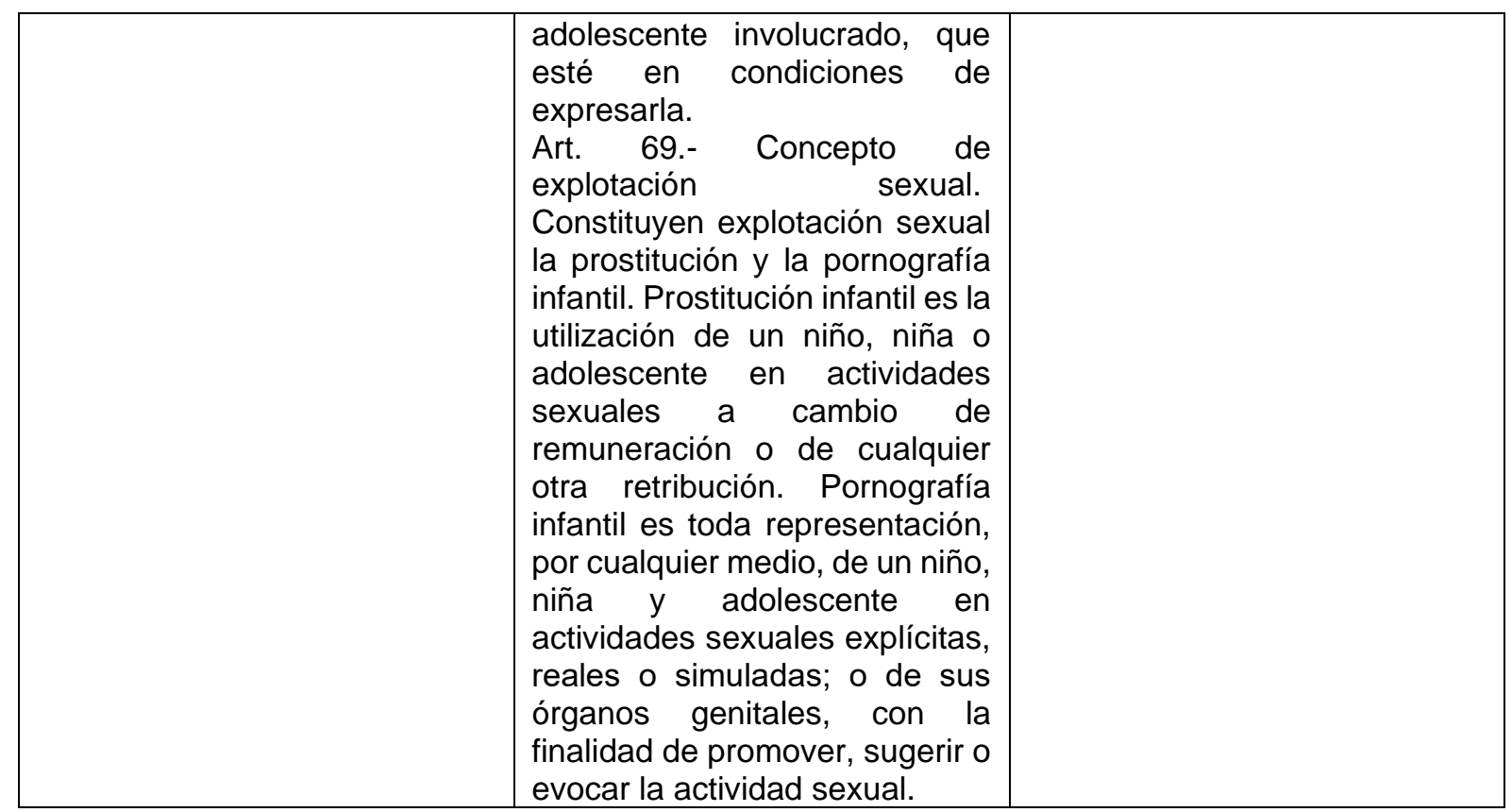

Elaboración: Los autores.

De acuerdo a los autores Salame Ortiz, Pérez Mayorga, y San Lucas Solórzano (2020), manifiestan que:

En los delitos sexuales, el consentimiento dado por la víctima menor de dieciocho años de edad es irrelevante; aquí también tiene presente dichas Reglas. - Las víctimas de estos delitos pueden ingresar al Sistema de Protección y Asistencia a Víctimas y Testigos (SPAVT) de la Fiscalía General del Estado. (p.357)

Se determinó que esta problemática ha venido transcendiendo hace varios años, hasta la actualidad, que uno de los problemas más evidentes es la falta de atención de los progenitores de los mismos, ya que, al tratarse de niños, niñas y adolescentes, es necesario que los padres tengan mayor cuidado sobre el entorno que rodea a sus hijos como el uso de redes sociales que se deberá hacer de manera contralada por un adulto. 


\section{Factores de riesgo de violencias sexuales en contra de NNA}

\begin{tabular}{|c|c|c|c|c|c|}
\hline 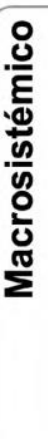 & $\begin{array}{l}\text { Pobreza. } \\
\text { Falta de oportunidades } \\
\text { educativas. } \\
\text { Deserción escolar. } \\
\text { Erotización del cuerpo por } \\
\text { razones culturales o fines } \\
\text { económicos. } \\
\text { Relaciones asímetricas de } \\
\text { poder basadas en género. } \\
\text { Trabajo infantil. }\end{array}$ & $\frac{.0}{\text { 을 }}$ & $\begin{array}{l}\text { Familias conflictivas: } \\
\text { relaciones asimétricas, } \\
\text { hacinamiento, abandono } \\
\text { paterno, lazos parentales } \\
\text { débiles, maltrato. } \\
\text { Ausencia de canales y } \\
\text { estilos de comunicación } \\
\text { adecuados. } \\
\text { Redes protectoras } \\
\text { insuficientes. } \\
\text { Debilidad institucional. } \\
\text { Ausencia de control y } \\
\text { supervisión de medios } \\
\text { comunicativos. }\end{array}$ & $\frac{\text { 을 }}{\frac{0}{0}}$ & $\begin{array}{l}\text { Historial de violencias } \\
\text { sexuales. } \\
\text { Baja autoestima. } \\
\text { Consumo de alcohol o } \\
\text { estupefacientes. } \\
\text { Uso precoz de las TIC. } \\
\text { Migraciones. }\end{array}$ \\
\hline
\end{tabular}

Figura 1. Factores de riesgo de violencias sexuales en contra de NNA. Fuente: Arrieta-Burgos, Duque-Pedroza, y Díez-Rugeles (2020).

\section{DISCUSIÓN}

Desde la perspectiva de los investigadores se considera que este acto ilícito que se comete debería tener su fin pues no es suficiente con que existan normas, pues considero que aquí interviene la falta de cultura de las personas, pues al saber que se está haciendo daño a una persona y en este caso a un niño, niña y adolescente, se debería tener más conciencia de que lo que se hace está mal, no se piensa en las consecuencias que estos actos conllevan.

También es necesario enfocarse en los métodos que se vienen aplican hasta la actualidad, pues no se ha obtenido un resultado favorables, pues los casos que se encuentran en internet son casos que han tendido que llegar hasta circunstancias graves para que se conozcan y se tomen cartas en el asunto, podría decir que quizás los medios de investigación que se utilizan en estos casos como es la pornografía infantil, no son totalmente suficiente, pues en diferentes sitio web todavía se siguen visualizando fotos de menores edad, la mismas que son vendidas a pedófilos 0 personas que desean para causar morbo o daño a la víctima. 


\section{CONCLUSIONES}

La pornografía infantil, es una problemática que ha transcendido por varios años, vulnerando los derechos de miles de niños, niñas y adolescente alrededor del mundo, dejando como consecuencia daños físicos y psicológicos en sus víctimas, afectando hogares de diversas formas y en muchos casos sin encontrar un culpable. El sistema de investigación que se utiliza en estos casos en muy deficiente, aunque se realizan rastreos de cuentas al igual que indagaciones, no se logra tener una respuesta correcta, como por ejemplo el acto de dicho hecho, como se ha mencionado anteriormente el internet es un tipo de plataforma amplia donde se puede tener información fácilmente e ingresas a dichos sitios con contenidos explícitos.

Se considera que la pornografía infantil al ser una forma de explotación sexual comercial, ya que para lo que este tipo de fotos o videos son usados, es un problema muy real que afecta el desarrollo de los niños, niñas y adolescente, aunque se encuentra establecida la sanción para este tipo de actos como es pena privativa de libertad de trece a dieciséis años, se sigue cometiendo y cada vez dejando más víctimas. Por otro lado, la información recolectada por medio de la metodología cuantitativa, deja muchas dudas como por ejemplo porque siendo un delito grave se sigue cometiendo, porque el Estado no crea un sistema más fuerte que pueda resolver este tipo de delitos, también que se bloqueen esos tipos de páginas que comparten este tipo de contenido.

\section{FINANCIAMIENTO}

No monetario.

\section{AGRADECIMIENTO}

A la Universidad Regional Autónoma de Los Andes, Ecuador; por motivar el desarrollo de la Investigación. 


\section{REFERENCIAS CONSULTADAS}

Arrieta-Burgos, E., Duque-Pedroza, A. y Díez-Rugeles, M. (2020). Delitos sexuales en contra de menores de edad en Colombia: caracterización criminológica y político-criminal. [Sexual crimes against minors in Colombia: criminological and politico-criminal characterization]. Revista Criminalidad, 62(2), 247-274. Recuperado de: https://n9.cl/k292y

Asamblea Nacional Constituyente de la República del Ecuador, (2008). Constitución de la República del Ecuador. [Constitution of the Republic of Ecuador] Montecristi. Registro Oficial 449 de 20-oct-2008. Recuperado de https://n9.cl/sia

Asamblea Nacional de la República del Ecuador. (2014). Código Orgánico Integral Penal [Comprehensive Organic Criminal Code]. Recuperado de https://n9.cl/g6sc

Astorga-Aguilar, C. y Schmidt-Fonseca, I. (2019). Peligros de las redes sociales: Cómo educar a nuestros hijos e hijas en ciberseguridad. [Dangers of Social Media: How to Educate Our Sons and Daughters in Cybersecurity]. Revista Electrónica Educare, 23(3), 339-362. Epub October 30, 2019. https://dx.doi.org/10.15359/ree.23-3.17

Congreso Nacional (2003). Código de la Niñez y Adolescencia. [Code of Childhood and Adolescents]. publicado por Ley No. 100. en Registro Oficial 737 de 3 de enero del 2003. Recuperado de: https://n9.cl/dtrec

Cruz Céspedes, A. (2019) Delito de pornografía infantil una realidad escolar y comunitaria. [Child pornography crime a school and community reality] Revista Arbitrada Interdisciplinaria KOINONIA, 5(4), 722-738. DOI: http://dx.doi.org/10.35381/r.k.v4i8.396

Mayer, L. (2014) Almacenamiento de pornografía en cuya elaboración se utilice a menores de dieciocho años: un delito asistemático, ilegítimo e inútil. [ Storage of pornography in the manufacture of which children under the age of eighteen are used: an assistive, illegitimate and useless offence. [Polít. crim. 9, (17),2757. Recuperado de: https://scielo.conicyt.cl/pdf/politcrim/v9n17/art02.pdf

Sáenz, J. (2020). El abuso sexual del menor de edad y su relación con el feminicidio infantil. [ Sexual abuse of minors and their relationship to child femicide] Conrado, 16(75), 87-92. Recuperado de: https://n9.cl/lh2j6

Salame Ortiz, M., Pérez Mayorga, B. y San Lucas Solórzano, M. (2020). La víctima en los delitos contra la integridad sexual.[ The victim in crimes against sexual integrity]. Revista Universidad y Sociedad, 12(3), 353-363.Recuperado de: https://n9.cl/5a6l 
Villabella, C. (2015). Los métodos en la investigación jurídica. Algunas precisiones. [Methods in legal research. Some clarifications] Instituto de Investigación Jurídica de la UNAM. Recuperado en: $\underline{\text { https://n9.cl/ylxad }}$

2021 por los autores. Este artículo es de acceso abierto y distribuido según los términos y condiciones de la licencia Creative Commons Atribución-NoComercial-Compartirlgual 4.0 Internacional (CC BY-NC-SA 4.0) 